\title{
Ginet on the Problem of Action Externalization
}

\author{
Katarzyna Paprzycka
}

Received: 6 November 2011 / Accepted: 30 May 2012/

Published online: 4 July 2012

(C) The Author(s) 2012. This article is published with open access at Springerlink.com

\begin{abstract}
Two questions have been discussed within the context of the action individuation debate. First, the question of action individuation proper - how many actions have been performed when one kills someone by shooting, for example. Second, the question of action externalization - what are the spatial and temporal boundaries of the killing and of the shooting. The internalists (Davidson, Hornsby) argue that the boundaries of actions do not reach beyond the skin of the individual. The externalists (e.g. Ginet) argue that the boundaries of actions do extend beyond the individual. The main problem for the externalists is to explain why so conceived actions are actions. In the paper I evaluate Ginet's response to this question but find it ultimately unsatisfactory.
\end{abstract}

Keywords Action theory - Action individuation · Temporal problem · Action internalism · Action externalism · Ginet

In a rich book that has not quite received the attention it deserves, Ginet (1990) has proposed a moderationist answer to the problem of action individuation. He himself does not think that the problem is significant and takes it to be a merely verbal issue (p. 70). Indeed, the time of the heated debate between the minimizers, maximizers and moderates is over. I suggest that there is a reason to look at this debate again. Ginet's account together with the problems it encounters is useful in bringing to focus some important problems.

While the question how many actions I have done at this moment might be as hot as the question how many angels there are at the tip of the pin, there is a deeper and more fundamental question that has been lurking in this debate, which is of fundamental interest to philosophy of action. This is the question of the very nature of action, in particular the question of whether it makes sense to think of our actions as

K. Paprzycka (ه)

Institute of Philosophy, University of Warsaw, Warszawa, Poland

e-mail: kpaprzycka@uw.edu.pl 
reaching into the world or as merely withdrawn to an inner realm. Those who have been inclined to think that actions reach into the world beyond the agent's skin, as is Ginet, must then address the question why one ought to think of so extended actions as actions. After briefly explaining Ginet's distinction between internalistically conceived basic actions and externalistically conceived concrete actions, I turn to the main question and consider Ginet's reasons for thinking that concrete actions are actions.

\section{The Problems of Action Individuation and of Action Externalization}

In Anscombe's classic (1963) example, a man moves his arm up and down, moves the pump, pumps water, supplies water to a nearby village, poisons the inhabitants. According to the minimalists (Anscombe 1963, 1979; Davidson 1971; Hornsby 1980; and more recently Pietroski 2000; Enç 2003), the man performs only one action, which can have various descriptions that involve the effects of the action (such as the inhabitants of the village being poisoned, for example). According to the maximalists (Goldman 1970, 1971), five actions ("acts" in Goldman's language) have been performed, which are related to one another by means of generation relations and for this reason they form one "act-tree". The moderationists find themselves somewhere in the middle. A useful way of thinking about their position is in terms of which of the four types of Goldman's generation relations they take to "generate" new actions and which they take to merely redescribe one and the same action. Some moderationists take only the causal generation relation to be truly "generative" (e.g. Dretske 1988; Thomson 1977). Others like Ginet (1990) or Thalberg (1977) take all but the augmentation relation, which has been problematic in its own right (Baier 1972; Smith 1978), to be generative in this sense. ${ }^{1}$

The debate between the minimalists and the moderationists is interesting in particular because it concerns yet another issue, which may be called the problem of action externalization or the problem of the boundaries of agency. The minimalists typically argue that actions do not extend beyond the bodily movements of the individual agent (in this sense they are internalists ${ }^{2}$ ) while moderationists argue that actions do extend beyond the individual agent and encompass events in the world that are suitably related to the agent (in this sense they are externalists). Some internalists (like Davidson 1971) argue that actions are to be identified with the movements of our bodies, while others (hyperinternalists like

\footnotetext{
${ }^{1}$ Actually Ginet has a nice way of doing away with augmentation generation: he eliminates the need for it by employing the other relations. Rather than allowing that there is a special generation relation between the action of voting and the action of voting with the right hand (which would count as an instance of augmentation generation on Goldman's account), he argues that both these actions are actions because they stand in some generation relation to other actions.

${ }^{2}$ While minimalists such as Davidson, Hornsby, Pietroski or Enç all argue that actions are to be identified with basic actions, which either are or are causes of bodily movements, there is at least a conceptual space for the position of an externalist minimalist, who could argue that only one event is an action, which is variously described but that it is not the basic action. Such a position would have to motivate the identification of another event with action, of course, but prima facie such a possibility is open.
} 
Hornsby 1980 or Pietroski 2000) argue that actions are to be identified with the causes of the movements of our bodies. ${ }^{3}$

The cardinal argument for the externalists has been the temporal problem (Davis 1970; Thomson 1971). Referring to Anscombe's example, let's suppose that the man did his pumping on Monday and that it took 4 days for the inhabitants of the village to die, so they died on Thursday. On the minimalist-internalist account, the action took place when the man's body was moving, ${ }^{4}$ i.e. on Monday. The man thereby killed the people in the village. But - so the objection goes - since we suppose that it was the man's pumping (on Monday) that caused the people to die (on Thursday), we must also claim that the man's killing of the people occurred on Monday, when the villagers were still alive. In fact, we must accept the paradoxically sounding claim that they died 4 days after the man killed them. ${ }^{5}$

The cardinal argument against the externalists, on the other hand, is the problem of action conceptualization. The problem is basically that while one may admit that we sometimes speak as if actions extend beyond the body of the agent (the temporal problem seems to be one piece of evidence for it), we do not have a conception of agency at our disposal, on which we could make sense of so extended actions. This argument (from activity) has been originally offered by Davidson (1971) and endorsed by other internalists (Hornsby, Pietroski):

Is it not absurd to suppose that, after the queen has moved her hand in such a way as to cause the king's death, any deed remains for her to do or to complete? She has done her work; it only remains for the poison to do its. (Davidson 1971, p. 57)

To this the externalists have sometimes responded that not all actions involve activity on the part of the agent (e.g. Thalberg 1977). But the problem is to see just how such responses comprise a comprehensive conception of agency.

If looked at in this light, it becomes evident that the debate on action individuation (between minimalists, moderationists and maximalists) and the debate on the boundaries of agency (between hyperinternalists, internalists and externalists) are in fact independent of one another. ${ }^{6}$ As a matter of historical fact, Goldman (1970), for instance, seemed to take no stand on the latter issue - he did not raise the temporal problem at all in the (1970) book, and later while he did acknowledge the problem in the (1971) article, he did not seem to realize that the categories that he developed in the book were not sufficient to deal with the problem (see also Lombard 1974). In any event, Goldman's maximalism is difficult to compare with the positions of Davidson (1971) or Thomson (1977), since he works with a very different notion of event.

\footnotetext{
${ }^{3}$ Hornsby (Pietroski follows her lead) distinguishes between two "kinds" of bodily movements: movements $_{\mathrm{T}}$ (where the verb is used in a transitive sense, as in " $S$ raised her arm") are identified with actions, which are identified with tryings, while movements (used in an intransitive sense, as in "S's arm rose") are identified with "sheer" movements of the body or bodily parts.

${ }^{4}$ Hyperinternalists (Hornsby, Pietrosky) will say that it happened just before the body started moving.

5 There are well-known responses to the temporal problem on the part of the internalists (see e.g. Bennett 1973; Hornsby 1979; Richards 1976; Thomson 1971; Vermazen 1978; Vollrath 1975).

${ }^{6}$ Theoretically, one could be a minimalist externalist or a maximalist externalist, though in either case, this would require the development of an appropriate theory of action. Maher's (2011) recent proposal might be thought to be close to a maximalist externalist account.
} 
In this paper, I will look at Ginet's answer to the problem of action individuation in the light of the problem of action externalization. I will argue that Ginet is quite wrong when he says that the debate is merely verbal. ${ }^{7}$ I will show further that Ginet's responses to the problem of action conceptualization are inadequate.

\section{The Problem of Action Conceptualization}

Let us reflect on the general structure of the problem of action conceptualization, especially as it relates to an externalist account of action. An externalist will typically distinguish between basic actions, which are often conceived of in ways that the internalist can find congenial (e.g. as bodily movements), and non-basic actions, which the externalist conceives in terms that violate the internalist strictures (e.g. as mereological sums of bodily movements together with their consequences).

The problem of action conceptualization is then a problem of responding to the question of what it is that makes actions actions. For an externalist, this problem divides into two subproblems:

(1) What makes basic actions actions?

(2) What makes non-basic actions actions?

One condition of adequacy for such an account ought to be that the answer to both (1) and (2) be based on a common unified conception of action. We can call this the condition of uniformity. A uniform conception of agency satisfies the condition of uniformity, while a non-uniform conception of agency does not satisfy it.

A non-uniform conception of agency opens itself up to the charge that actions of one of those types are actions merely in a manner of speaking. The objection is that even if we accept that the theory has provided an answer to question (1), then since the answer to question (2) is different, we should not think of the conglomerates of basic actions and their consequences as anything other than conglomerates of basic actions (the only actions there are) and their consequences.

Ginet's account is a non-uniform account of action. He offers different answers to these two questions. Basic actions are actions in virtue of the actish phenomenal feel that accompanies them, while there is no additional actish phenomenal feel that accompanies non-basic actions. He is thus open to the charge just described. But his account is of special interest because one of the responses to question (2) that is available to him appears to provide an answer to this sort of objection. We will see, however, that closer scrutiny reveals that the appearance is deceiving.

\section{Ginet's Externalism}

Ginet offers a moderationist account of action individuation, which is also externalist. After briefly sketching his account, in particular his account of basic actions and nonbasic actions ("concrete actions", as he calls them), I will argue that Ginet fails to

\footnotetext{
${ }^{7}$ Ginet refers to the debate on action individuation, which - as I have just shown - is entangled in the debate about externalization of action.
} 
provide a uniform conception of action, which could explain what makes concrete actions actions. Ginet offers at least three ways of responding to the problem of action conceptualization, but his responses are problematic.

I begin by setting the stage and briefly introducing Ginet's notion of an action designator, which plays a central role in the definition of action that Ginet offers. After introducing the distinction between (internalistically conceived) basic actions and (externalistically conceived) concrete actions, I show that Ginet's account is subject to a version of the temporal problem.

\section{Action Designators and the Definition of Action}

Ginet begins by introducing the notion of a personal-event designator, a nominalized expression which designates a personal event (e.g. " $S$ 's falling down the stairs at $t\rangle$, «S's raising $S$ 's arm at $t\rangle)$. He puts forward as a "definition of action" an inductive definition, which tells us when a designator designates an action.

According to Ginet, all actions begin with a mental exertion (a mental action), which has a characteristic actish phenomenal quality. Some of these mental actions have a variety of effects ( $S$ 's raising an arm, $S$ 's frightening off a fly) or other consequences ( $S$ 's voting “yes"). The designators in the mentioned examples also designate actions (whether the same actions or different ones is then a matter for the account of individuation).

Ginet proposes the following definition of action:

(D) « $S$ 's $V$-ing at $t »$ (provided that it is a canonical designator) ${ }^{8}$ designates an action if and only if either:

(i) it designates a simple mental occurrence that has the actish phenomenal quality or

(ii) there is an action-designator « $S$ 's $X$-ing at $t^{*} »$, such that « $S$ 's $X$-ing at $t »$ GEN «S s $V$-ing at $t^{*} »{ }^{9}$

Two points need clarification. First, a canonical designator of a personal event is a noun phrase that picks out a personal event uniquely. Whether or not a given descriptor is a canonical designator is contingent on the circumstances. One and the same descriptor, e.g. "Sally jumped up on Christmas morning in 2000" can be canonical in some circumstances (when Sally jumped up only once) but not in others (if Sally continued jumping up all morning, say).

Second, the GEN relation (general generating relation) needs to be explained. Intuitively speaking, the GEN relation is meant to capture what Goldman means by generation relations, though GEN is both wider and narrower in scope than

\footnotetext{
${ }^{8}$ All of Ginet's definitions are conditional on the descriptors being canonical designators of a personal event. I simplify the definitions by omitting the conditional clauses and will simply assume that whenever a descriptor is used, it is assumed that it is a canonical designator of a personal event.

9 There is a third clause of the definition, which is designed to handle actions composed of other actions. Ginet's example is the action of typing a 5-letter word, which he conceives to be an aggregate of five actions of typing individual letters. His treatment of this example, and of the whole category, would demand serious reflection. Certainly if one lets oneself be influenced by results in cognitive science, then at least on some (e.g. connectionist) accounts of what is going on, the action of typing a 5-letter word is not a simple sum or even a sequence of five individual actions. I will consistently ignore this aspect of Ginet's account.
} 
Goldman's relations. The GEN relation obtains between those designators, which are connected in our ordinary speech by the 'by' preposition in various contexts. Ginet does not claim that in the sentence " $S$ killed the villagers by pumping poisoned water", the preposition 'by' functions as a relation (Hornsby 1980 has objected to just such an idea). Rather he uses such sentences to define a BY relation in the following way:

(B) «S's $V$-ing at $t » \mathrm{BY} « S$ 's $X$-ing at $t^{*} »=\operatorname{def} « S$ 's $V$-ed at $t$ by $X$-ing at $t^{*} »$ is true

The GEN relation is introduced to cover the inverse of the BY relation as well as various contexts in which the preposition 'by' occurs.

The definition of GEN includes three clauses, which I will explain below by examples:

(G) «S's $X$-ing at $t »$ GEN «S's $V$-ing at $t^{*} »=\operatorname{def}$

(1) «S's $V$-ing at $t^{*} » \mathrm{BY} « S$ 's $X$-ing at $t »$,

(2) « $S$ 's $V$-ing at $t^{*} »$ is of the form « $S$ 's $Y$-ing at $t^{*}$ by $X$-ing at $t »$

(3) « $S$ 's $V$-ing at $t^{*} »$ is of the form « $S$ 's $X$-ing at $t$ in circumstances $C »$, and some personal-event designator has the BY relation to « $S$ 's $X$-ing at $t\rangle$ because it has the BY relation to « $S$ 's $X$-ing at $t$ in circumstances $C »$.

First, whenever there is a BY relation between descriptors $D_{x}$ and $D_{y}$, there is a GEN relation between $D_{y}$ and $D_{x}$. For example, $\langle S$ 's pumping poisoned water at $t\rangle$ GEN «S's killing the villagers at $t^{*} »$ because the sentence « $S$ killed the villagers at $t^{*}$ by pumping poisoned water at $t »$ is true. Second, Ginet wants the GEN relation to obtain in the following case, where the "generated" designator includes the use of the 'by' preposition: «S's pumping poisoned water at $t » \mathrm{GEN}$ « $S$ 's killing the villagers at $t^{*}$ by pumping poisoned water at $t \gg$. Third, and last, Ginet is worried about a descriptor including the mention of circumstances in which an action has taken place. Consider the example of $S$ who is pumping water by moving his arm up and down. In such a case, Ginet argues, there will be circumstances, in virtue of which it is the case that $S$ 's moving his arm up and down is an instance of pumping (e.g. that $S$ holds the pump handle with his arm). Ginet wants to insure that there is a GEN relation not only between the designators « $S$ 's moving his arm up and down at $t »$ and « $S$ 's pumping water at $t$ » which is covered by (G1) but also between the designators « $S$ 's moving his arm up and down at $t »$ and « $S$ 's moving his arm up and down at $t$ in the circumstances when $S$ holds the pump handle with his arm». ${ }^{10}$

Having explained the terms occurring in definition (D), let me note that though Ginet presents it as a "definition of action", it is an almost purely extensional definition. It does not tell us how the concept of action is connected to other concepts (with the exception of the base clause), rather it tells us which expressions designate

\footnotetext{
${ }^{10}$ The question whether the GEN relation captures all that it should capture is a separate question. One might wonder, for example, whether the designator « $S$ 's moving his arm up and down at $t$ in the circumstances when $S$ holds the pump handle strongly with his arm» (or even « $S$ 's moving his arm up and down at $t$ in the circumstances when $S$ holds the pump handle with his arm and the temperature is $20 \mathrm{C}$ )) should not be counted as a designator of action. While such designators may include "irrelevant conditions", it is not clear that this should prohibit them from picking out actions. If one thinks that the condition added is irrelevant then one might take account of this in the theory of action individuation and argue that all of the above designators pick out the very same action. I will abstract from such worries, however.
} 
actions. It delimits what counts as an action but it does not do very much to illuminate the concept.

One might quarrel with the adequacy of Ginet's delimitation too. For example, he rejects negative actions from counting as actions with a simple note that "they are not actions in the sense [he is] interested in" (Ginet 1990, p. 1n).

\section{Basic Actions and Concrete Actions}

Let us suppose that (D) provides an adequate delimitation of action designators. Usually in any given case, numerous action designators will be applicable:

«S's moving his arm up and down»

«S's pumping water»

«S's supplying water to a nearby village»

«S's poisoning the inhabitants»

The GEN relation can be used to order such designators into an action tree. The problem of action individuation is to answer the question how many actions do the designators in one action tree designate. The minimalists answer "one" (the internalist minimalists then identify the one action with the basic action that lies at the root of the tree). The maximalists answer "all" (with the possible exception of semantically equivalent designators). The moderationists answer "neither one nor all".

Ginet belongs to the last group. He distinguishes three types of actions: simple mental actions, concrete actions, which are "composed of an action as a core plus a layer of consequence or circumstance" (p. 65), and conjunctions of actions, which (as announced in footnote 9) we will be ignoring.

The basic actions, which he also calls volitions, are the mental actions with a characteristic actish phenomenal feel. Ginet does not think that we must always be aware of this feel but that it is always possible for us to be aware of it. One might, of course, raise questions why a phenomenal feel ought to be responsible for anything being action-like, but let me leave Ginet's conception of mental actions alone.

Concrete actions, on the other hand, are "events with a layered structure" (p. 50) as Ginet puts it. At the core of the action lies a mental action, while various "circumstances" or "results" constitute other layers. Let's look at three examples Ginet gives:

(1) "I ... find it natural ... to think of the action designated by ... (B.6) «S's raising her hand just after she has heard the chair of the meeting say "And those opposed?" at $t_{1}$ » as including among its parts not only the action designated by [ $\ll S$ 's raising her hand at $\left.t_{1} »\right]$, but also the circumstance of that action implied by B.6, namely, the chair's having said what he did just before that action." (p. 50)

(2) "The action designated by (B.7) « $S$ 's voting against a proposal at $t_{2}$ »adds another layer of circumstance to that designated by B.6, namely, the existence then and there of a convention according to which, if $S$ raises her hand just after the chair has said "And those opposed?", then she thereby votes against the proposal before the meeting." (p. 50)

(3) " $" S$ "s jumping further this morning than she ever has before»designates an action that includes not only a particular jumping of $S$ 's this morning, but the 
circumstance that prior to it $S$ had not jumped as far as she did in that jump."(p. 50)

One might think that Ginet thinks of the circumstances as being timeless abstract objects. This is indicated by the fact that he does not change the time index in the designators $« S$ 's raising her hand at $t_{1} »$ and $« S$ 's raising her hand just after she has heard the chair of the meeting say "And those opposed?" at $t_{1}$ » even though the latter includes the circumstance of the chair's having said what he did just before that action. But this seems to be a sleight of hand.

In the case of the other two examples Ginet is quite clear that the circumstances he speaks of are concrete events and states that reach beyond the individual and beyond the time of the core action - both into the future as well as, in some cases, into the past. In case (2), the circumstance comprises "all the particular events and states in virtue of which it is true that there existed then and there that convention" (p. 50). He does not say what these are but it is hard to imagine that it could be anything falling short of everybody's (or at least most people's) dispositions to interpret the behavior in this way. If so then the action is enlarged tremendously. The resulting concrete action has parts - other people's dispositions - that are quite disjoint from the core action at the center. The only "connection" between those parts and the core action is via the designator.

In case (3), the added circumstance "includes all of $S$ 's previous jumps" (p. 50) and so again the resulting action becomes extended into the past, so to speak. This sounds really quite paradoxical but Ginet does not comment on this. To say that the action includes all of $S$ 's previous jumps is to say now that the action of jumping further than $S$ ever did starts when $S$ made her first jump, so starts much earlier than $S$ started jumping on the occasion in question. Suppose we want to know how much time it took Jane to jump. Suppose that on that occasion Jane's jumping took $5.25 \mathrm{~s}$. But on Ginet's account, if on that occasion Jane jumped further than she ever has before, then if we ask "How much time did Jane's jumping further than she ever has before take?", we might have to answer that it took her more than 15 years. Things would get even worse if she broke her speed record. The answer to the question "How much time did Jane's breaking her life record on $100 \mathrm{~m}$ take?" might again permit an answer in years rather than seconds.

Suppose that Jane breaks a world record in swimming $100 \mathrm{~m}$ free style. Since this action now includes not only the mental action and its bodily consequences but also all the previous swims by numerous other swimmers, Jane's action of breaking a world record begins before she was born.

These statements seem just unacceptable. They could be thought of as comprising what could be called a "pretemporal" problem. The classical temporal problem arises for minimalism since our intuitions seem to speak in favor of our actions reaching as far as their consequences, so to speak. Ginet embraces those intuitions by allowing that concrete actions have their consequences as their parts. He is thus not committed to the paradoxically sounding claim of the minimalists that

(4) The man killed the inhabitants of the village 4 days before they died.

(referring back to the example mentioned earlier). However, since Ginet's concrete actions can have as their parts also the antecedents of the basic actions, he is committed to the paradoxically sounding claim, for example, that: 
(5) Jane's breaking a world record began before she was born.

or perhaps also what might appear to be just a more colloquial restatement:

(6) Jane began breaking a world record before she was born.

Both claims appear problematic.

The susceptibility of Ginet's moderationism to a version of the temporal problem is somewhat ironic since one of the main motivations for moderationism has been to overcome the temporal problem. Yet, if one takes the idea that concrete actions are real wholes in the world seriously, it is difficult to see how, on Ginet's account, these statements should turn out false. ${ }^{11}$

\section{Why are Concrete Actions Actions?}

Having sketched Ginet's account of actions, let me now turn to the central question. Why should we think of them as actions? The question is particularly pressing for the case of concrete actions, which, as Ginet acknowledges, have parts that are not actions. This question is of interest to us because only a well-grounded answer to this question can justify an externalist conception of action.

I will investigate three responses (two given by Ginet himself and one given on his behalf) but will find them all wanting.

Let us first consider what Ginet says in response to the worry that concrete actions might not be thought of as actions because they involve non-actional parts. ${ }^{12}$ Speaking of examples (1)-(3), he says:

In these examples... an action and a result or a circumstance of it together form a significant whole that the agent made to exist by that action, such a whole as the agent could have intended to make exist (though she need not have so intended). This whole can be thought of as something that this person qua agent contributed to the world: Its parts that are not actions of the agent were either caused by him or else were already in place so that his action completed the whole. Therefore this whole can be thought of as itself an action of that agent, despite the fact that not all of its parts are actions of his. (p. 50)

Two sorts of responses seem to be invoked in this passage: first, that concrete actions should be thought of as actions because they are possible objects of intentions, and second that they should be thought of as actions because they are an agent's contribution to the world. I will examine them in turn. However, neither of these responses ties in with the "definition of action" proposed by Ginet, which is indicative of the fact that he does not offer a uniform account of action.

\footnotetext{
${ }^{11}$ It should be noted that the pretemporal problem does not affect those versions of the moderationist view that take only the causal generation relation to be truly "generative" (Dretske 1988; Thomson 1977).

12 Actually, this is not to say that when one performs two actions - plays with a toy when 2 and digs a hole when 62 , one thereby performs the action of playing-with-a-toy-when-2-and-digging-a-hole-when- 62 . Perhaps there are circumstances when we would count this to be an action, but it is precisely the purpose of a conception of action to explain or clarify what is involved in our calling an action an action.
} 
Ginet's first suggestion is that concrete actions (such as jumping further than the agent has before) are actions because they can be the objects of intentions. Just as the agent can intend to jump so she can intend to jump further than she has before.

Let me note from a start that this response does not explain why concrete actions are actions. Even if it were successful, it would at very most show that we treat them as actions by allowing them to be the objects of intentions. But it is not successful.

The main problem is that the object of intention is always specified discursively. In other words, there is a gulf between the action description that is involved in the specification of the content of an intention and the action which this description picks out. How the gulf is to be bridged will be a matter of dispute between among others the minimalists, the moderationists and the maximalists, as well as the internalists and the externalists. In the context of the dispute in question, the assertion that concrete actions are actions because they are the objects of intentions is tantamount to stamping one's feet.

\section{Action as an Agent's Contribution to the World}

The second way of thinking about concrete actions Ginet offers is to think of them as the agent's (qua agent, Ginet adds) contribution to the world. This metaphor is again unhelpful for Ginet's purposes.

On a more limited version of moderationism, nonbasic actions would be wholes made of the basic actions and all those events that were the effects of actions (e.g. Dretske 1988; Thomson 1977). Ginet's way of thinking about why the nonbasic actions should be thought of as actions of the agent might be plausible on such an approach since the effects of the basic actions are brought about by the agent indirectly, so to speak.

But Ginet is quite liberal in allowing already existing circumstances to be parts of actions. To repeat, in the case of jumping further than one ever has before, the action "includes all of [the agent's] previous jumps" (p. 50). Presumably, a world record jump includes all the previous record jumps by other jumpers.

It is very hard to see how the agent could be credited with contributing such wholes to the world. In the case of the world record, the agent clearly contributes her jump but not the other jumpers' previous world records. The other jumps were part of the world already - the agent did not need to contribute them at all. Likewise, in the case of the agent's own past jumps - they were already contributed to the world, this time by the agent herself, so in the morning when the agent jumps further than she has before, there is nothing over and above that morning jump that she contributes.

This might be thought to be uncharitable. What the agent is meant to be contributing is not the non-actional parts but rather the wholes of which those non-actional parts are but parts. It is only because the agent made the jump that a world record has been broken. In other words, if we represent the agent's jump by ' $\alpha_{S}$ ' while the other world records jointly by ' $\beta$ ', then $S$ 's world record is the whole $\alpha_{S} \oplus \beta$. The sense in which $S$ contributes the action to the world is that:

(C) If $S$ had not done what she did (viz. $\alpha_{S}$ ), neither $\alpha_{S}$ nor $\alpha_{S} \oplus \beta$ would exist. 
One problem with understanding this principle as underlying the actionhood of concrete actions is that by this token anything that has $S$ 's action as a part is itself an action. In fact, the whole universe itself would be $S$ 's action. Since if $S$ had not done what she did, the universe (which includes $S$ 's action) would not exist. (C) is thus far too weak to render the idea of the agent's contribution to the world intelligible.

The Action Transmissive Character of the BY Relation

Here is another sort of response that could be provided on behalf of Ginet, though he does not offer it with this intention. Ginet's theory could be thought of as involving two tiers. The first tier consists of simple mental actions, which are actions in virtue of the actish phenomenal feel that accompanies them. The second tier consists of concrete actions (and action aggregates), whose status as actions is now being questioned.

One sort of response to which Ginet might resort concerns his earlier observation about the action-transmissive character of the BY relation. Ginet says:

The preposition by is marvelously handy for our purposes, because its meaning is such that « $S V$-ed by $X$-ing» is true only if $S$ 's $X$-ing was involved in $S$ 's $V$-ing in some way such that if $S$ 's $X$-ing was an action, then so was $S$ 's $V$-ing. (p. 16)

Using the definition of the BY relation, we can formulate this thought as the Action-Transmission Principle:

(atp) For any two canonical personal-event designators $D_{x}, D_{y}$, if $D_{y} \mathrm{BY} D_{x}$, then for every action $a_{z}$, if $D_{x}$ designates $a_{z}$, then there is an action $a_{w}$ such that $D_{y}$ designates $a_{w}$.

Since the GEN relation is a generalization of the BY relation, one could argue that the following more general principle holds:

(ATP) For any two canonical personal-event designators $D_{x}, D_{y}$, if $D_{x}$ GEN $D_{y}$, then for every action $a_{z}$, if $D_{x}$ designates $a_{z}$, then there is an action $a_{w}$ such that $D_{y}$ designates $a_{w}{ }^{13}$

Ginet could then argue that while the presence of the actish phenomenal feel provides an explanation of why basic actions are actions, the (ATP) principle explains why concrete actions (and aggregate actions) are actions. Concrete actions are actions because they have inherited the action status from the actions that are their parts by virtue of the (ATP) principle. Consider the concrete action designated by « $S$ 's moving his arm up and down at $t »$ which stands in the GEN relation to « $S$ 's pumping water at $t »$, in virtue of the circumstance that $S$ is holding a working water pump handle. (ATP) guarantees that $S$ 's pumping water is an action because $S$ 's moving his arm up and down is an action and $S$ pumps water by moving his arm up and down.

\footnotetext{
${ }^{13}$ One should note on a side an affinity between the (ATP) principle and the accordion effect introduced by Feinberg (1965) and generalized further by Davidson (1971). See also recent discussion by Bratman (2006).
} 
If we are to use (ATP) for this purpose, the principle must be justified. I can see at least three sources of justification for (ATP): from a conception of action, from an acceptance of minimalism, from our linguistic knowledge. Not all of these possible ways of grounding (ATP) are on a par. It would be ideal if (ATP) could be justified by a conception of action one holds. If that were the case then the main problem for externalism (of the conceptualization of action) would be solved. However, Ginet cannot claim justification from any of these sources. Let's consider them in turn.

Given the two-tiered structure of Ginet's account of action, the use of (ATP) to ground the actional status of concrete actions would be in fact circular. To repeat, mental actions (the first tier) are claimed to be actions in virtue of the actish phenomenal feel. Concrete actions (the second tier) are claimed to be actions in virtue of the (ATP) principle and the fact that they are recursively related to the mental actions. Such a conception of action, which uses the (ATP) principle, cannot serve to justify the very principle in question.

The second source of justification for (ATP) comes from minimalism. The minimalist position can be expressed in the following way:

(min) For any two canonical personal-event designators $D_{x}, D_{y}$, if $D_{x}$ GEN $D_{y}$, then for every action $a_{z}, D_{x}$ designates $a_{z}$ iff $D_{y}$ designates $a_{z}$.

The (ATP) principle is a straightforward logical consequence of (min). The only problem is that Ginet rejects minimalism and so cannot use it to justify (ATP).

The last source of justification, which is also suggested in the quote, is linguistic. Ginet seems to suggest that the (ATP) principle is ultimately tied to the meaning of the preposition 'by'. This would mean that whenever we are inclined to say that $S \mathrm{~V}$ ed by $X$-ing, if we treat $X$-ing as an action, then we also treat $V$-ing as an action. Prima facie this seems to be a very suspect contention. It is suspect because it is unclear who 'we' stands for. As far I can see, there are two options. Either 'we' refers to the linguistic community of competent English-language speakers or it stands for a part of that community that has also some philosophical education in particular in philosophy of mind or action.

There are problems on both interpretations especially in view of the fact that it is widely agreed by philosophers of action that there are no simple syntactic markers of action designators. It seems therefore that one would have to rely on the intuitions either of the English populace at large or a philosophical community. It is a notorious fact, however, that certainly philosophers working in the area are divided in their intuitions. It suffices to cite as an example Ginet's own footnote (p. 1n) where he announces that he is simply not interested in capturing a notion of action, on which negative actions count as actions.

Let me, however, put forward two cases, which I think falsify the (ATP) principle, though I am fully aware of the fact that intuitions may be divided on these points. The first involves a consequence of an action, which is so far removed from the original action and so accidental that we might no longer be inclined to attribute it as an action to the agent. The second involves also a consequence of an action but one over which the agent has no control. I should note that I do not put forward those cases as knockdown cases for the (ATP) principle. Rather, I want to illustrate the contention that in view of the fact that these cases may claim some intuitive appeal, the project of justifying the (ATP) principle by appeal to linguistic intuitions alone falls. 
Let us consider the first case. Suppose that Joe goes to the cinema and while involved in watching the movie, he tries to adjust his sitting position, in the process of which he kicks the back of the seat in front of him. It turns out that a married couple in great turmoil has been sitting in front of him. This kick is just the last straw - it unleashes an emotional avalanche, which results in the couple ultimately divorcing. Joe has caused the couple to ultimately divorce by kicking the back of the seat, but is this really something that he has done (albeit unintentionally)? I do not think so. Consider a different sort of scenario, in which Joe also kicks the back of the seat in front of him but the kick is not an action of Joe's - it is a result of a sudden spasm in his leg. We may suppose that the remainder of the causal chain is the same as before. In such a case, no philosopher of action would be inclined to judge the causing of divorce as an action of Joe's. But the point is that these cases are really not so far apart from one another. ${ }^{14}$ The agentive input of Joe's into the process of the couple's divorcing seems to be very close in the case when he inadvertently kicks the back of the seat and in the case when his leg kicks the seat in a spasm.

Let us turn to the second sort of case. Suppose that in moving my arm I cause a certain water molecule $M$ to move off its course. We may perhaps say that I moved molecule $M$ off its course by moving my arm. Is this something I have done? I will be inclined to say that this is something that I happened to do but because I have no particular skill to systematically affect the movement of water molecule $M$, or any other particular molecule, moving it off its course cannot be thought as something that I did.

As stressed, these cases are not meant to be put forward as obvious counterexamples to (ATP) but rather as potential ones in the sense that they reveal some intuitions about agency, which at least could be developed further into an account of action. This is sufficient not to falsify (ATP) but rather to falsify the claim that (ATP) can be justified by appeal to language alone. I hope that I have done enough to show that we harbor at the very least conflicting intuitions and so that we cannot appeal to language alone in trying to justify (ATP). If so, however, then Ginet is left without an answer to the problem of conceptualization of action.

One might object here that perhaps it is enough that (ATP) can be supported by some intuitions. Those intuitions do not establish (ATP) but at least justify it to some extent. But this sort of response seems insufficient for the purposes to which (ATP) is employed here. The invocation of the principle was to serve as a justification for the treatment of concrete actions as actions. I have noted that ultimately a convincing response would invoke a conception of agency. Ginet's conception, we said, is twotiered - on the first tier he invokes the actish phenomenal feel to justify the status of mental actions as actions, whereas on the second tier (we are now supposing) he invokes the action-transmissive character of the BY relation to justify the status of concrete actions as actions. I have already noted that this does little to help us in tying

\footnotetext{
${ }^{14}$ I should note here, of course, that such intuitions can only find home on a non-minimalist account. If one is a minimalist then the question we are asking here is only whether the various descriptions pertain to an event that is an action. If it is, then causing the divorce is one of the things that the agent did - albeit unintentionally. I have argued elsewhere (Paprzycka 1997) that one may speak here not of something the agent did, but rather of something that the agent happened to do. But note that the fact that there are philosophical intuitions that pull in one and the other direction is quite sufficient for my purposes.
} 
the concept of action with other concepts. The response is thus intensionally inadequate, so to speak. But if it were a fact that (ATP) can be established then the response might at least be extensionally adequate. Our having noted that there are intuitions, which contradict (ATP) serves to call into question even the extensional adequacy of Ginet's proposal.

\section{Conclusion}

I want to draw three conclusions from this discussion. First, I hope that I have given some reasons for disagreement with Ginet's opinion that the action individuation debate is a merely verbal dispute, if only because it is entangled with a different nonverbal (or at least as non-verbal as philosophical discussions get) dispute about the boundaries of agency. Second, I have shown that Ginet's account is subject to a version of the temporal problem. Third, I have argued that although Ginet's externalistic stance is noteworthy, he does not provide the answers that we should expect from an externalist account. The account of action he offers is not uniform and hence illequipped for providing an answer to the problem of action conceptualization. Ginet's own responses to the problem as well as one suggested in his book have turned out to be inadequate.

This last conclusion might well play into the hands of the internalists, who will argue that they alone can offer a coherent account of action but that such an account needs to be circumscribed, at the very least, by the barrier of the agent's body. Alternatively, the conclusion can be taken as providing some guidelines for an externalist account of action. A first step in this direction is, I believe, to divorce the idea of action from the idea of event (as has been suggested by Bach 1980, for example). An argument for this, however, will require a separate paper.

Open Access This article is distributed under the terms of the Creative Commons Attribution License which permits any use, distribution, and reproduction in any medium, provided the original author(s) and the source are credited.

\section{References}

Anscombe, G. E. M. (1963). Intention (2nd ed.). Ithaca: Cornell University Press.

Anscombe, G. E. M. (1979). Under a Description. Nous, 13, 219-233.

Bach, K. (1980). Actions are not Events. Mind, 89, 114-120.

Baier, A. C. (1972). Ways and Means. Canadian Journal of Philosophy, 1, 275-293.

Bennett, J. (1973). Shooting, Killing and Dying. Canadian Journal of Philosophy, 2, 315-323.

Bratman, M. (2006). What is the Accordion Effect? Journal of Ethics, 10, 5-19.

Davidson, D. (1971). Agency. Reprinted in D. Davidson, Essays on Actions and Events. Oxford: Clarendon, 1980.

Davis, L. H. (1970). Individuation of Actions. Journal of Philosophy, 67, 520-530.

Dretske, F. (1988). Explaining Behavior: Reasons in a World of Causes. Cambridge: The MIT Press.

Enç, B. (2003). How We Act: Causes, Reasons, and Intentions. Oxford: Oxford University Press. 
Feinberg, J. (1965). Action and Responsibility. Reprinted in A. R. White (Ed.), The Philosophy of Action. Oxford: Oxford University Press, 1968.

Ginet, C. (1990). On Action. Cambridge: Cambridge University Press.

Goldman, A. I. (1970). A Theory of Human Action. Englewood Cliffs: Prentice-Hall.

Goldman, A. I. (1971). The Individuation of Action. Journal of Philosophy, 68, 761-774.

Hornsby, J. (1979). Actions and Identities. Analysis, 39, 195-201.

Hornsby, J. (1980). Actions. London: Routledge \& Kegan Paul.

Lombard, L. B. (1974). A Note on Level-Generation and the Time of a Killing. Philosophical Studies, 26, $151-152$.

Maher, C. (2011). Action Individuation: A Normative Functionalist Approach. Philosophical Explorations, 14, 99-116.

Paprzycka, K. (1997). Social Anatomy of Action. Toward a Responsibility-Based Account of Agency. Ph.D. Dissertation: University of Pittsburgh.

Pietroski, P. M. (2000). Causing Actions. Oxford: Oxford University Press.

Richards, N. (1976). E Pluribus Unum: A Defense of Daivdson's Individuation of Action. Philosophical Studies, 29, 191-198.

Smith, J. A. (1978). Goldman on Act Individuation. Australasian Journal of Philosophy, 56, 230-241.

Thalberg, I. (1977). Perception, Emotion, and Action. Oxford: Basil Blackwell.

Thomson, J. J. (1971). The Time of a Killing. Journal of Philosophy, 68, 115-132.

Thomson, J. J. (1977). Acts and Other Events. Ithaca: Cornell University Press.

Vermazen, B. (1978). Actions in the Causal Series. Philosophical Studies, 33, 287-299.

Vollrath, J. F. (1975). When Actions Are Causes. Philosophical Studies, 27, 329-339. 